\section{The cutting edge in the blunt space: an anthropological construct of auxiliary nurse midwives' social world in the community}

\section{Avanish Kumar,' Meerambika Mahapatro \\ 1 Management Development Institute, Gurgaon; ${ }^{2}$ National Institute of Health and Family Welfare, New Delhi, India}

\section{Abstract}

Auxiliary nurse midwives (ANMs) are the most peripheral health providers and manage the rural health sub-centre in a community. They mediate directly between the community and the health system for the management of Maternal and Child Health Programme in India. The purpose of this study was to find out the role of cultural factors, such as ANMs' caste, age, marital status, being non-resident in the working village and other social factors regarding their acceptance in the community. The study is exploratory and qualitative. The area of study was a multi-caste remote village, Mavaibhachan, in Kanpur Dehat district of Uttar Pradesh, India. Data were collected through in-depth interviews and fieldwork notes taken during and immediately after the interviews with ANMs, and thematically analyzed. Our results show that if ANMs belong to a different caste group, do not live in the working village and are relatively younger, they are socially insecure and stressed and the community hardly accepts them. Despite direct interface with the community, their social status and lowest position in the health system is reflected in acceptability and recognition. The position of ANMs needs to be strengthened, within society and the health system. In order to make public health services effective and efficient the health system has to reduce stratification based on role and status.

\section{Introduction}

Auxiliary nurse midwives (ANMs) are the most peripheral health providers, and as a permanent functionary of health system, they manage the rural health sub-centre (SC) in a three-layered health system, interact directly with the community thus managing the Maternal and Child Health Programme in India. ${ }^{1}$ Considering their status as front-line or cutting-edge, grass-root level health providers in the health organizational hierarchy, and the gamut of functions performed, their work is fundamental to the success of the health program. ${ }^{2}$ Recent policy shifts in National Rural Health Mission (NRHM) have made it clear how it is ANMs' responsibility ${ }^{3}$ to manage all aspects of health and family welfare., ${ }^{4,5}$ Other tasks include performing national health programmes and support the International Classification of Diseases (ICD) and other outof-reach governmental services. ${ }^{6}$ Consequent to the multiple functions performed by ANMs, they are expected to do home visits to meet the health needs of every household in the community, especially the poor and vulnerable sections of population in rural areas. ${ }^{7,8}$ They attempt to be on regular contact with their area population both individually and collectively and cover the area on foot, which often extends to socially and spatially excluded communities.

With their active work and involvement in the community, they are expected to provide quality and timely health care. The limited time spent by workers in their jobs is a central factor in low levels of outreach effort. ${ }^{9-11}$ Auxiliary nurse midwives are expected to live in the SC village and be available around the clock for providing their service. ${ }^{12,13}$ of the 20,521 SCs in Uttar Pradesh, India (September 2005), 32\% had ANM quarters moslty inhabited by ANMs $(5,183$ out of 6,494$)$. Yet, given that two-thirds of the SCs did not have staff quarters, it would be hardly surprising if ANMs rarely showed up for work. ${ }^{13,14}$ The role of ANMs has markedly changed over the past four decades, ${ }^{15}$ however, their training and infrastructure support remains stagnant.

The efficiency and effectiveness of ANMs is more complex because their area of operation is embedded with social-political dimensions. A bigger problem lies in the increasing demand, diminishing resources and less attention paid to systemic operational problems that limit the functioning of services. ${ }^{8,12}$ This further gets accentuated because many ANMs have to face the consequence of such a mechanism of inefficiency allocation, chronically absence of human resources and doctors, and patients who are routinely charged for some services meant to be free. ${ }^{9,10}$ Unlike hospitals or clinics, in villages, their gender, caste and even age, rather than disease and medicine, do influence consumers' decision on health services. ${ }^{16}$ Auxiliary nurse midwives work with the people confronted with illiteracy, poverty, unemployment, deep-rooted social customs and local caste-based politics. They have to provide services where people lack health culture. ${ }^{17}$ Here, the clinical practice of medicine is not an idealized application of literacy and declarative system of knowledge learned in basic science courses, medical clerkships and practice, but like any other exchange, it is an arena for constructing new schemata by intuitively and systematic analogically modifying
Correspondence: Meerambika Mahapatro, National Institute of Health and Family Welfare, Baba Ganganath Marg, New Delhi, India. Tel. +91.011.2616.5959 - Fax: +91.011.2610.1623.

E-mail: meerambika@rediffmail.com

Key words: auxiliary nurse midwife, community, community health worker.

Contributions: the authors contributed equally.

Conflict of interests: the authors declare no potential conflict of interests.

Received for publication: 8 January 2013

Revision received: 17 January 2013.

Accepted for publication: 2 February 2013.

This work is licensed under a Creative Commons Attribution 3.0 License (by-nc 3.0).

(C) Copyright A. Kumar and M. Mahapatro, 2013 Licensee PAGEPress, Italy

Healthcare in Low-resource Settings 2013; 1:e10 doi:10.4081/hls.2013.e10

old domains of knowledge that interact with new experiences embedded in often mundane, emergent settings. ${ }^{18}$

The effect of these social factors in their routine work and acceptance in the village goes unnoticed..$^{19}$ A prolonged non-response to emotional and interpersonal stressors on the job has an implication on inefficacy. It also depends on auxiliary nurse midwives' experiences revolving around the quality of their relationship with the community, social status, their position in the occupational hierarchy of the health services, the nature and location of their health work, and their support mechanisms (professional, infrastructural, and personal).

The present paper aims to find out how social factors like ANMs' caste, age, marital status and being non-resident in the working village and other social factors contribute to their acceptance in the community, which in turn influences the quality of care rendered by ANMs.

\section{Materials and Methods}

The study design is exploratory and used a qualitative method. The participants' observation was carried out by staying in the village for six months. The area of study was Mavaibhachan, a multi-caste remote village in Kanpur Dehat district of Uttar Pradesh, India. During fieldwork, basic facilities such as electricity and toilets were far to be reached from the village. 


\section{Study design and setting}

The study design is exploratory and used a qualitative method to capture the worldview of the ANMs. The area of study was a village called Mavaibhachan located in Ghatampur block in Kanpur Dehat (rural) district of Uttar Pradesh, India. As the name suggests, Kanpur Dehat is one of the most backward districts of Uttar Pradesh. Ghatampur block was purposively selected as one of the most social-economically backward block, having poor health indicators and a multi-caste village. The two dominant caste groups are the religious superior caste of Brahmins and the politically and economically dominant caste of Yadavs. The conflict between the two castes in local politics is reflected in their daily activities which further impact the health seeking behavior, as ANMs come from one dominant caste, i.e. Brahmin. The SC was located in a house of a Brahmin. Being a widow, her regular visit to the village was question on her character by the other caste groups. During our stay in the village for six months, we interviewed and observed the work space of ANMs of different villages of Ghatampur block, Uttar Pradesh. To triangulate our observations, we conducted indepth interviews of 20 fellow ANMs working in the district.

\section{Sample size and frame}

Twenty ANMs of Ghatampur block were selected for in-depth interviews till data saturation. The method utilized was intensity sampling.

\section{Data collection}

Data were collected through in-depth interviews. Quasi-non-participant observations were carried out to understand the interaction between community men and the ANMs. The questionnaire was open-ended and case narration was recorded. The narratives from questionnaire, field notes and diary were transcribed and thematically analyzed. Some of the important questions asked were i) how ANMs' caste influences the routine work schedule; ii) whether ANMs' age and stage (marital status) affect their work; iii) ANMs as outsiders or non-resident in the village; iv) ANMs' assistance delivery, sex of the child, support (professional and interpersonal) mechanisms; v) ANMs' training; etc. Informed consent was obtained from all participants: participation was entirely voluntary and confidentiality assured. Health administration and community members were informed about the purpose of study.

\section{Results}

In ANMs' everyday life, their interactions with people and their social intercourse in relation to their environment, community, caste and gender as social actors interpret and give meaning to their professional world. The ANMs were young, inexperienced to this reallife work environment challenges because they joined the job just after the usual institute training. Unlike controlled environment in hospitals, in the community the ANMs' medical efficacy is confronted with social constraints. This is the more so because ANMs are women and work in a conservative patriarchal caste, and class and gender-based rigid social settings.

Our analysis focuses first on the social structure, ANMs' caste, assistance delivery and sex of the child, their training as health providers, and their professional and interpersonal support within the healthcare system. Subsequent sections examine the political quality of their facilities, deficiencies in ANMs' performance and the targets.

\section{Auxiliary nurse midwives' caste}

In multi-caste villages of Kanpur Dehat which have a patriarchal and caste-based social stratification system - ANMs are Brahmin (the upper caste group) and this constitutes a problem. In Mavaibhachan, intercaste rivalry existed between the Yadavs (traditionally involved in dairy-related occupation and politically dominant in the region, though lower in the caste hierarchy) and the Brahmins. As a consequence of political conflict, cases of murder, retaliatory looting and house burning took place, which is reflected in daily interaction. Despite repeated efforts, ANMs are not able to overcome their caste barriers with their technical competence only. As a result, the efficiency of the system and the effectiveness of services get affected. Since the $\mathrm{SC}$ of the public health system is located in a rented house within the village, ANMs get support to house SC in a Brahmin's family. Auxiliary nurse midwives are categorized more as a Brahmin rather than healthcare providers. Auxiliary nurse midwives in the field have to face various social risks. The expectation of the community in terms of ANMs as an ideal womanhood puts them in question. This is more so, because they alone have to visit regularly to the SC that is in Brahmins' house. Few villagers do raise their eyebrows before ANMs as they visit the SC located in other families' house. In order to build their case against ANMs, Yadav community maligns their character and credentials. Similarly, an ANM from a lower caste reported that she faced discrimination in a higher caste group where she was not allowed to touch people who sit in a chair and insulted her in various ways. Auxiliary nurse midwives as a cutting-edge health professionals working in SC as a last mile health infrastructure lose their efficacy in a closely-stratified community. Therefore, real-life clinic of ANMs is constantly mediated with cultural impediments and social infrastructure.

The devolution of power and decentralization of public services have exposed ANMs to community politics and prejudices. Another kind of harassment occurred when elected leaders - sarpanch - demanded special services at home in their village, but their requests were not met. Thus, they complained against ANMs or rated their performance as poor in the appraisal dossier, or asked for transfer ANMs from the village. The problem gets worse because in the current policy, the sarpacnh (elected village head) is to sign the yearly progress and performance of ANMs.

\section{Auxiliary nurse midwives' assis- tance delivery and sex of the child}

The household level demand is destined to sons. ANMs and midwives reported that delivery of a female child fetched them less reward which was often expressed in less token money: approximately Rs. 50/- (around $1 \$$ ) for a female child, while Rs. 500 (10\$) and dress as a gift for a male child. A repeated delivery of girl child by ANMs is often considered as bad hand or unlucky for the family. Therefore, ANMs are not called for delivery anymore in the village.

In another case, a man from the village brought a lady with whom he had extra-marital relation for forceful abortion. When the ANM denied doing so, she was threatened with dire consequences. This forced her to abort the fetus without infrastructure and technical support leading to further complications due to abortion. Sometimes, due to similar pressure, ANMs are forced to adopt illegal practices of sex selective abortion.

\section{Auxiliary nurse midwives as out- siders or non-resident}

The notion of outsider for ANMs by the community exists in Uttar Pradesh. In Kanpur Dehat, ANMs being outsiders has a negative impact. Auxiliary nurse midwives spent a large part of their service attempting to establish amicable relations with largely unfamiliar communities. They also try to establish a strong, credible presence in the community because they are seldom posted in their native villages. While building relations with strangers, they face sexual abuse, tease and harassment. An extended conversation with opposite sex is often quoted by the villagers as a default in the role model of ANMs: they are looked upon and tagged by the villagers as having extra-marital affairs. Since ANMs' work requires them to speak openly about contraceptives with men, they are viewed as women of loose morals. This negative social image and vulnerable status within the health system 
makes them an easy prey to sexual harassment.

All the ANMs reported that most of the victims of molestation are the ANMs who are the outsiders from different districts. One block of Kanpur Dehat is infamous for criminality. Once, an ANM got molested and the news got printed in the Hindi newspaper (state edition). Her family got to know about it and the ANM was forced to continue the job for her livelihood because her wage had a high impact on the economic stability of her households. Over time, ANMs encounter numerous obstacles in their work but do not dare to contemplate a job switch. The fear is socialized in the ANMs community and has a direct impact on the health program. Among the consequences, ANMs' visits to their respective area become fewer, their staying in the block area rather than at the SC or in the village; even though they are on night duty and do not prefer to travel at night. Auxiliary nurse midwives report that they have numerous reasons for preferring not to live in their SCs as personal safety is a major concern, especially for unmarried women, who are most vulnerable to sexual harassment.

\section{Auxiliary nurse midwives' training}

Most trained ANMs felt that too much information had been imparted in a too short time in a real-life clinic. They were trained on providing public services, but seldom they were trained in communication and negotiation skills at the village. This fails to build trainees' confidence, a vital asset in an unassisted health workplace which requires independent decision making. Moreover, their cloistered existence in the school does little to prepare them for work in unfamiliar, often uninviting, village communities. The threat of sexual harassment and abuse mars the careers of most ANMs, but trainees are not informed of their legal rights or channels of redress. In the end, ANMs learn their lessons of village-level health work not in training schools, but while negotiating the numerous hurdles they encounter in everyday real-life clinics.

\section{Professional and interpersonal support}

Auxiliary nurse midwives reported that they need professional support to help them carry out the tasks assigned to them particularly at a sub centre (SC) level where they are deprived of the re-assuring environment of a health site compared to the ANM posted in the primary healthcare (PHC). They also reported that, though transitory supportive supervision is given on technical guidance, they also need moral support and encouragement to handle the SC more confidently. The situation is highly unpalatable when ANMs visit the SC and its doors are locked.

The SCs were usually located at the village periphery or outside the protection of the main village cluster. They were often dark and dingy, sometimes located in rented rooms or government made structures with lack of electricity and drinking water facilities, i.e. they were not adequately or uniformly equipped and also lacked this basic amenity. Their physical working conditions fall far short of that ideal with essential equipment and supplies. The vaccines and medicines are often supplied in respect to the requirements. As a result, community people asked to visit in the next session tikka nehi hai (unavailability of dose) in some of the PHCs and SCs. The sessions are organized weekly and, in some areas, children are already late for their scheduled vaccination. These inadequacies affected the ability of ANMs to work with any degree of confidence in the community. Besides being overburdened, ANMs cited the inadequacy of facilities, equipment, and medicine stocks. They also complained about the lack of proper accommodation and inadequate transport facilities.

\section{Discussion}

The outcomes of clinical encounters in the social world were influenced by various social circumstances. Socio-demographic characteristic of patients, ANMs' professional and social background, and the organization of practice settings appear to determine ANMs' responses to patients' complaints at least partially. ${ }^{14}$ The medical setting in the hospital creates conditions under which every modes of communication and thinking initially take precedence over formal concerns with production of objective medical knowledge. ${ }^{9,20}$ Nonetheless, in the social world of care and cure, ANMs and patients may have different health perspectives and therapeutic agendas. ${ }^{21}$

The representation of lower castes (chiefly scheduled castes) and upper castes, as evidenced by the caste variation among ANMs of different ages, has increased the acceptance. Another important variable which is related to but not dependent upon geographical location is the resources of the practitioner's disposal. ${ }^{22}$ In the course of ANMs' life, their everyday interactions with people and social intercourse in relation to their environment, community, caste and gender as social actors, interpret and give meaning to their professional world. ${ }^{7}$ This is not to say that all actions are thought out, which would imply a highly rational view of behavior. It does, however suggest that all actions, even the most routine and automatic, are subject to interpretation and scrutiny in the local reality. ${ }^{23}$ Young, unmarried or not having children ANMs were facing more problem in the working and getting accepted in the village. Older age, personal characteristics, place and length of employment, and work schedule had an effect. This outcome of nonacceptance of ANMs may be a result of sociocultural differences that may be a reflection of difficulties in the work condition. ${ }^{24,25}$

Negative conditions where the workload extensively exhaust individuals with little remuneration and reward can disrupt the quality and quantity of service ${ }^{26}$ by making it a blunt edge. Rather than loading all desired activities on the ANMs under the pretext of integration, different types of health personnel should be provided for implementing a particular task. There is a need to separate functions and skills that can be integrated in one person and those that require different types of skills and appropriate training. ${ }^{27}$ Improved infrastructure facilities available at the health centre can increase the mobility and social assistance/help by increasing the value of their work station. ${ }^{28}$ Alternative systems may be arranged to meet socio-cultural adaptation for better acceptance of ANMs. Decrease identity and social status gap between doctors and ANMs may increase acceptance of ANMs in the community very well and may be seen as a first step in the establishment of a quality framework. These concerns have to be adequately emphasized in India's public health system. However, this will have to be backed up by uniformly available and accessible health institutions and practitioners. It became clear that it is not enough to confine integration to single programs. It must bring together programs with common strategies and resource requirements such as technological, organizational and administrative. Finally, it must also build a shared evaluation and monitoring mechanisms of conceived linkages and objectives so that they may be revised if required. ${ }^{27,28}$

\section{Conclusions}

With the increasing devolution of public services, the role of ANMs has become much more complex and significant. The current epistemological characteristics of medical theory taught in the training centre cannot be manifested directly. The health system needs to build the capacity of ANMs of evolving medical specialization and social diagnostic practices. Although the health program has been devolved upon a bottom-up approach, system and structure still remain top-down. Despite direct interface with the community, ANMs' lowest status in the health system gets reflected in their acceptability and recognition. One of the reason behind outplays of gender, age and caste identity is due to ANM low status in the health system. The solution is provided by a system which is more flat in structure and can provide dignity and status for ANMs. The elevation in social status of ANMs and capacity to negotiate medical effica- 
cy will overcome social barriers. Along with these changes, social security of ANMs can be promoted through a deputing policy in their native districts. Therefore, in order to provide services at the cutting-edge, the health system needs to constantly sharpen its edge with building skills of management and structure without stratification.

\section{References}

1. Barua A, Kurz K. Reproductive healthseeking by married adolescent girls in Maharashtra, India. Reprod Health Matter 2001;9:53-62.

2. Jeffery P, Das A, Dasgupta J, Jeffery R. Maternal mortality and morbidity: is pregnancy getting safer for women? Reprod Health Matter 2007;30:172-8.

3. Grover D. Reena S, Kaishtha KC, et al. RCH: the role of ANM. Available from: http://prcs-mohfw.nic.in/writereaddata/ research/222.pdf Accessed: 25/12/2011.

4. Karasek R, Theorell T. Healthy work: stress, productivity, and the reconstruction of working life. New York, NY: Basic Books; 1990.

5. Government of India. National Rural Health Mission. Mission report 2005-2012. New Delhi: Ministry of Health and Family Welfare, Government of India; 2005.

6. Malik G. Role of auxiliary nurse midwives in National Rural Health Mission. Nurs J India 2009;100:88-90.

7. George A. Persistence of high maternal mortality in Koppal District, Karnataka, India: observed service delivery constraints. Reprod Health Matter 2007;15:91102.
8. Iyer A, Jesani A. Women in health care: auxiliary nurse midwives. Mumbai: Foundation for Research in Community Health; 1995.

9. Pinto S. Development without institutions: Ersatz medicine and the politics of everyday life in rural North India. Cult Anthropol. 2004;19:337-64.

10. Jesani A. Limits of empowerment. Women in rural health care. Econ Polit Weekly 1990;25:1098-103.

11. Koenig MA, Foo HC, Joshi K. Quality of care within the Indian family welfare programme: a review of recent evidence. Stud Family Plann 2000;31:1-18.

12. Duggal R. Is the trend in health changing? Econ Polit Weekly 2006;41:1335-8.

13. Mehrotra S. Public health system in UP: what can be done? Econ Polit Weekly 2008; 43:46-53.

14. Paul S, Balakrishnan S, Gopakumar, et al. State of India's public services: benchmarks for the states. Econ Polit Weekly 2004;39:920-33.

15. Iyer A, Jesani A. Barriers to the quality of care: the experience of auxiliary nursemidwives in rural Maharashtra. In: Koenig MA, Khan ME, eds. Improving quality of care in India's family welfare programme. New Delhi: Population Council; 1999. pp. 210-37.

16. Mishra R. Female health workers: problems and implications. Econ Polit Weekly 1997;32:2791-3.

17. Cicourel AV. Diagnostic reasoning in medicine: the role of clinical discourse and comprehension. Actes Rech Sci Soc1985;60: 79-89.

18. McCombie SC. The politics of immunization in public health. Soc Sci Med 1989;28:843-9.
19. Bonair A, Rosenfield P, Tengvald K. Medical technologies in developing countries: issues of technology development, transfer, diffusion and use. Soc Sci Med 1989;28:769-81.

20. Dietsch E, Mulimbalimba-Masururu L. The experience of being a traditional midwife: living and working in relationship with women. J Midwifery Wom Heal 2011;56: 1542-2011.

21. Deodhar S. Training of ANMs: an assessment. FRCH Newsletter 1994;8:1-3.

22. Ritchie J, Dick D, Lingham R. Report of the committee of inquiry into the care of Christopher Clunis. London: MIND/ COHSE; 1994.

23. Horobin G, McIntosh J. Time, risk and routine in general practice. Sociol Health Ill 1983;5:312-31.

24. Cicourel AV. Doctor-patient discourse. In: van Dijk TA, ed. Handbook of discourse analysis. London: Academic Press; 1985. pp.193-202.

25. Maslach C, Schaufeli WB, Leiter MP. Job burnout. Annu Rev Psychol 2001;52:397422.

26. Srinivasan K, Shekhar C, Arokiasamy P. Reviewing reproductive and child health programmes in India. Econ Polit Weekly 2007;42:14-20.

27. Qadeer I. Health planning in India: some lessons from the past. Soc Sci 2008;36:51 75.

28. Mohan P, Iyengar S, Brahmawar S, et al. Auxiliary nurse-midwife: what determines her place of residence? J Health Popul Dev Countries 2003;23:1-16. Available from: http://www.longwoods.com/home.php?cat= 394 Accessed: 23/12/2011. 